\title{
CDISC SEND Standardized Disposition Term Terminology
}

National Cancer Institute

\section{Source}

National Cancer Institute. CDISC SEND Standardized Disposition Term Terminology. NCI

Thesaurus. Code C89968.

The terminology that includes concepts relevant to the Clinical Data Interchange Standards Consortium (CDISC) Standard for the Exchange of Non-clinical Data (SEND) standard disposition terms. 